\title{
Using Movies in EFL Classrooms: A Study Conducted at the English Language Institute (ELI), King Abdul-Aziz University
}

\author{
Raniah Hassen Kabooha ${ }^{1}$ \\ ${ }^{1}$ King Abdul Aziz University, Saudi Arabia \\ Correspondence: Raniah Hassen Kabooha, King Abdul Aziz University, Saudi Arabia. E-mail: \\ rkabouha@kau.edu.sa
}

Received: January 3, 2016 Accepted: February 18, 2016 Online Published: February 22, 2016

doi: 10.5539/elt.v9n3p248 URL: http://dx.doi.org/10.5539/elt.v9n3p248

\begin{abstract}
The present study sought to examine the attitudes of Saudi English as a foreign language (EFL) learners as well as teachers towards the integration of English movies in their classes as a tool to develop students' language skills. Fifty female intermediate level students studying English in their Preparatory Year Program (PYP) in the English Language Institute (ELI) at King Abdul-Aziz University (KAU), Jeddah, Saudi Arabia, participated in the study. Questionnaires were administered to the students to investigate their perceptions towards the integration of English movies in their classes to develop their language skills. The researcher also conducted semi-structured interviews with both students and teachers to explore their perceptions towards the use of movies in their classes. In addition, teachers were required to write reflective journals regarding the use of movies in their classes. The findings of the study indicate that both students as well as teachers had positive attitudes towards the use of movies in their classes to improve students' language skills. The study offers pedagogical implications for EFL instructors with respect to the integration of films in their classrooms to improve students' language learning. Well-selected movie materials could enhance students' language learning process and increase their motivation to learn the target language.
\end{abstract}

Keywords: classroom research, language learning, language skills, motivation, movies, technology.

\section{Introduction}

The acquisition of a second or foreign language is arguably one of the most cognitively challenging undertakings a person may experience in his or her lifetime. In the kingdom of Saudi Arabia, most students have studied English as a foreign language for at least six years before they enter university. Nevertheless, most of them remain incompetent in their ability to use the language. The reasons for this failure are varied and complex. One justification for this issue may be that too much attention has been devoted to intensive reading-analysis of words, sentences and grammar (Al-Akloby, 2001). Many Saudi EFL teachers focus on grammar decoding and skill drilling. In addition, it is been argued that the materials used for teaching the language in most of the Saudi EFL classes are dull and unstimulating.

Recently, many language instructors, material designers, and scholars have been interested in investigating the effectiveness of a variety of strategies and methods that can be employed in the EFL classes to facilitate the learners' mastery of language skills and optimize the teaching and the learning process. A number of studies have revealed that movies can become an integral part of the curriculum due to their significant effect on the development of the basic language skills: reading, listening, speaking, and writing (Baratta \& Jones, 2008; Martín \& Jaén, 2009; Ismaili, 2013; \& Rokni \& Ataee, 2014; Yaseen \& Shakir, 2015 ).

The findings of several studies which have been conducted to investigate the impact of using movies in EFL classrooms indicate their powerful role in the teaching and the learning process. According to Seferoğlu (2008), films provide authentic language input and a stimulating framework for classroom discussions. They also provide a realistic view of the language and culture providing insights into the reality of life of native English speakers (Florence, 2009). Studies have also reported some advantages to the integration of movies into foreign language classes. For instance, movies can capture the students' attention towards the target language (Tognozzi, 2010); increase the students' motivation to learn the language (Ruusunen, 2011); supply good material to teach conversations (Martín \& Jaén, 2009); and improve the students' awareness of the target language culture (Zhang, 2013). Moreover, the integration of movies in the EFL/ESL classes can also improve the students' academic 
writing skills (Baratta \& Jones, 2008). Khan (2015) believes that the "visuality" of movies can facilitate comprehension and understanding for the language learners in an ideal visual context, which makes it an effective language-teaching tool. She further argues that movies offer a variety of methods and resources for teaching the target language, helping students to improve their listening and communicative skills.

Although, research has indicated the impact of movies on the development of overall literacy skills (Baratta \& Jones, 2008; Martín \& Jaén, 2009; Ismaili, 2013; Rokni \& Ataee, 2014), very few works examined the perceptions of EFL teachers and students towards the integration of movies in their classrooms as a tool to improve students' language skills. It should also be noted that there are no studies conducted in the cultural context of Saudi Arabia. Therefore, the current study aims at investigating the perceptions of Saudi EFL teachers and students towards integration of movies into their classrooms as a pedagogical tool to improve students' language learning.

\section{Literature Review}

A review of the literature on the integration of movies in the EFL/ESL classrooms provides that movies are greatly effective in the language classroom for a number of ends. It has been shown that movies can be exploited in the English classroom to enhance students' critical thinking skills (Eken, 2003), their recognition of pragmatic usage and fluency (King, 2002), and to improve comprehension-based learning (Swaffar \& Vlatten, 1997).

Movies as a method of teaching have also been found to be an effective motivator for studying language (Seferoğlu, 2008; Florence, 2009; \& Ismaili, 2013). In addition, movies teach the students through the use of paralinguistic features where the students use the gestures, pauses, actions, and reactions of the characters to understand the gist of the dialogues (Keene, 2006). They are not only effective motivators, they have also been found to stimulate the imagination of the students (Kusumarasdyati, 2004). Keene (2006) considers movies unbeatable in providing contextual information and developing interactional skills compared to audio cassettes and CDs. They provide a plethora of knowledge about language providing input in terms of literary, drama, cinema and language aspects thereby promoting critical thinking and other language skills of the students (Eken, 2003, as cited in Keene, 2006).

The research conducted by Pezdek, Lehrer, \& Simon (1984) suggests that movie fragments help enhance memory and recovery of information in reading and listening. Film can also help in developing writing skills through providing interesting and motivating clues, assisting in comprehension and production of foreign language input and output (Hanley\& Herron, 1995). Another study that supports the use of movies in classrooms is that of Herron and Hanley (1992) which concludes that using movies offers background information that activates prior knowledge, which is essential in stimulating the four language skills.

However, movies should be chosen with educational objectives in mind. The theme and content should be such that they should not prove to be purely entertainment for the students rather rich in content while being enticing and motivating for the students to watch (Stephens, Ascencio, Burgos, Diaz, Montenegro, \& Valenzuela, 2012). Keene (2006) cautions the use of movies, as they are a "technology that is mainly used in the learners' home for entertainment, escapism and relaxation all of which encourage a passive form of viewing" (p. 223). This necessitates the teacher to facilitate interactive viewing. King (2002) also stresses the importance of choosing appropriate movies in such a way that they are not too complex for the level of understanding to the target students and the content should not prove to be offensive to the students. Several studies also show that movies help in increasing the confidence of the students in speaking as they learn how to use certain words and to pronounce correctly (Seferoğlu, 2008; Florence, 2009; \& Mirvan, 2013).

There are also several studies that go deeper in investigating the use of movies in EFL classrooms. Some of them include the effectiveness of using subtitles compared to not using them (King, 2002; Massi \& Blázquez, 2008; Hayati \& Mohmadi, 2011; Rokni \& Ataee, 2014). Some studies compared the effect of viewing of the movie in full versus viewing them in segments (King, 2002). In addition, there are studies that examined the effect of using the extra material available in DVDs as teaching materials (Massi \& Blázquez, 2008), using of movies in enhancing reading (Mirvan, 2013) as well as giving an introduction to the movie before the students watch it (King, 2002; Brown, 2010; Li, 2012; \& Stephens et al., 2012).

According to the study conducted by $\mathrm{Li}$ (2012), giving a five minute introduction to the movie followed by a brainstorming session between the students and teacher to discuss the theme, what the movie would contain, new vocabulary and expressions would be very effective in the comprehension of the movie. Keene (2006) observes that giving an introduction to the movie and characters also helps sustain interest in the movie. He also discusses the importance of having pre-viewing activities because if the students do not have any activities, they might adopt passive viewing which is the norm at home. Some may even see it as an extracurricular and therefore it is 
unimportant to be given too much attention. Fisher and Frey (2011) also hold the same view that there should be activities before, during and after watching the movie to keep the students attentive thereby fulfilling its pedagogical use.

A review of several studies reveals that although movies are a very powerful tool in second language acquisition, they can only achieve their full pedagogical potentials with the use of effective strategies and tasks. The activities used to exploit the movie depend on what the instructor wishes to convey to his students. The same clip can convey different messages depending on the strategies and activities used. The importance of using effective strategies is also seen in other studies like that of King (2002), Keene (2006), Brown (2010), Li (2012), and Stephens et al. (2012). Although the literature is varied in terms of the use and effectiveness of using movies in the language classroom, there have not been many studies conducted to investigate the perceptions of Saudi EFL students as well as teachers towards the integrating movies into their classrooms to improve students' language skills. The current study attempts to address this particular issue.

The following research questions guided the research process:

1). What are the students' perceptions towards the integration of movies in their classrooms to improve their language skills?

2). What are the teachers' perceptions towards the integration of movies in their classrooms to improve the students' language skills?

\section{Methodology}

The researcher in the current study adopted a mixed-method approach in order to answer the aforementioned research questions, which is an approach to research in which the researcher incorporates quantitative and qualitative dada, and then derives interpretations depending on the integrated strengths of both data to present a thorough comprehension of the research problem (Creswell, 2015). The study employed a 5-point Likert Scale questionnaire to find out to what extent the students believed watching movies could help them improve their language skills. The researcher also conducted semi-structured interviews with a set of open-ended questions that examined both the students' and the teachers' perceptions towards the integration of movies in their classrooms to improve students' language skills. In addition, teachers were required to write reflective journals about this experience and think critically of their classes when they used movies as a method of teaching.

\subsection{Participants}

The participants in the study were 50 Saudi female intermediate level students studying English in the English language Institute (ELI) at the King Abdul Aziz University. The participants aged between 18 and 21 years old. Two female EFL teachers participated in the study. Two classrooms in the ELI were utilised for the purpose of the study with 25 students in each class. The present study employed a convenience sampling method to select participants, which entails "drawing samples that are both easily accessible and willing to participate in a study" (Teddlie \& Yu, 2007, p. 78).

\subsection{Administration}

Students in the present study devoted thirty minutes of their four-hour English class to conduct the movie activity over a period of six weeks. They watched four movies throughout that period. The integration of movies in the classrooms was conducted following the steps suggested by Seferlogu (2008) for using feature films in language classes:

Previewing activities: At the beginning of the activity, students engaged in some warm-up previewing activities such as guessing the topic of the movie from its title and some pictures, some questions to activate their background knowledge and schemata. Students were also provided with some key vocabulary and potentially difficult expressions to facilitate their understanding of the movie scenes. According to Author (2008), activating students' background knowledge and schemata can greatly improves their retrieval and retention of information as it brings it to awareness as well as facilitates their learning of the new vocabulary and enhance their motivation to learn the target language.

Viewing movie segments: In the current study, the short sequence approach was adopted instead of viewing the whole movie. The students watched the movie clips in their classroom which had a computer with a DVD drive and a data projector.

Viewing worksheets: Students were provided with worksheets that drew their attention to particular details in the movie and required them to answer very short questions.

Vocabulary and pronunciation notebooks: Throughout the six weeks, students were required to keep a 
vocabulary and pronunciation notebook in which they noted down all the new vocabulary and phrases learned. The students' task was to filter through all the newly heard/learnt vocabulary and specify where they came across the word.

Movie summaries: The students were asked to write one short review for any of the movies they watched throughout the module. They were provided with a set of guidelines that helped them in the process of writing the review. Their reviews included a short summary of the movie, their reactions to the theme, the characters and the audio and visual imagery in the film, and how they were emotionally touched by the movie. Students were provided with some specific questions such as, Did you learn anything from the film? What was it? Write a few sentences about your opinion of the movie and what you took away from watching it. What did you like best about the movie? What did you like least about the movie? Why?

Group work \& a role-play: Students were responsible for preparing a movie role-play in a group of four to six members; they selected and memorised a scene of the movie to role-play in class. In the role-play, group members were required to work in collaboration and that each had an equal share. The instructors demonstrated one movie segment to the class in order to model the activity, and then the students worked in groups where they prepared and acted out the movie scenes throughout the six weeks.

\section{Results}

5.1 The Questionnaire

Table 1. Numbers in percentages*

\begin{tabular}{|c|c|c|c|c|c|c|}
\hline No. & Question & $\begin{array}{l}\text { Strongly } \\
\text { Agree }\end{array}$ & Agree & Neutral & Disagree & $\begin{array}{l}\text { Strongly } \\
\text { Disagree }\end{array}$ \\
\hline 1 & $\begin{array}{l}\text { Do you think watching movies in English has a } \\
\text { beneficial effect on improving your English } \\
\text { language skills? }\end{array}$ & 68 & 20 & 4 & 8 & 0 \\
\hline 2 & $\begin{array}{l}\text { Are you interested in learning English and } \\
\text { participating in classroom discussions if the teacher } \\
\text { uses movies as teaching materials? }\end{array}$ & 72 & 16 & 4 & 8 & 0 \\
\hline 3 & $\begin{array}{l}\text { Do you think watching movies in the classroom } \\
\text { makes it easier for you to learn English? }\end{array}$ & 68 & 20 & 4 & 8 & 0 \\
\hline 4 & $\begin{array}{l}\text { Do you agree that watching movies motivates you to } \\
\text { learn English? }\end{array}$ & 52 & 32 & 8 & 8 & 0 \\
\hline 5 & $\begin{array}{l}\text { Does the integration of movies in the EFL classroom } \\
\text { decrease your anxiety and tension in language } \\
\text { learning? }\end{array}$ & 60 & 20 & 12 & 8 & 0 \\
\hline 6 & $\begin{array}{l}\text { Do you agree that movies can help in improving } \\
\text { your vocabulary acquisition? }\end{array}$ & 56 & 24 & 12 & 8 & 0 \\
\hline 7 & $\begin{array}{l}\text { Do you think your English teacher should use more } \\
\text { movie viewing activities in the classroom to help } \\
\text { you improve your language skills? }\end{array}$ & 68 & 20 & 4 & 8 & 0 \\
\hline
\end{tabular}

A descriptive statistical analysis of the answers given by the students revealed that on a general level, students considered the integration of movies in the classroom as effective. The majority of the participants found movies to be useful in developing their language skills as well as keep them interested. Sixty-eight percent of the students strongly agreed that films in English could facilitate the learning of the English language. More than half of the participants agreed that they are more motivated and interested in learning English if their teachers use films in the classrooms. Approximately eighty percent of the students agreed to the statement that the use of movies in their lessons reduced their anxiety in learning English. Eighty percent of them also agreed that movies can help improve their vocabulary acquisition. Eighty-eight percent of the participants believed that their EFL teachers should integrate more movie viewing activities in their classrooms to help them improve their language skills. 


\subsection{The Students' Interviews}

The interviews were analysed to complement the results of the questionnaires. Eight participants were interviewed after the viewing sessions. All the students agreed that the use of films provided an authentic and meaningful context for them to learn English. As they watched the movies with plenty of conversations between native speakers, they felt a need to learn to speak English naturally and fluently in order to communicate with others. Two of the participants commented,

S1:"I think movies help a lot in learning English, especially with speaking and listening. They provide us with more opportunities to hear native speaking of English and learn how they interact in normal conversations...."

S3: “...we can learn then how to use English more fluently in our daily lives and be more engaged when communicating with people."

The participants also reported that movies reduced their language anxiety and increased their confidence in speaking English after listening and being exposed to the authentic language used in the film. They mentioned that they have learned some slang words and phrases, which rarely appear in their textbook. Three students mentioned,

S1: “.....there was a group discussion about the characters and the events of the movie; this can help us in practicing our oral skills..."

S4: “...watching movies can develop our speaking skills.....we heard the native speakers' accent and may be this can help us to pronounce and communicate in a better way"

S6: "Listening and watching the characters in the movie talking can help us improve our speaking skills..., movies can teach us the real English, we can learn some slang words and phrases and use them in conversation."

The interviews have indicated that movies are very motivating for EFL learners. The participants in the current study found themselves more involved in the English classes with the use of films and they were more willing to interact in English. Three participants commented,

S2: "The lessons are boring with only textbook and worksheets; we like to learn English by watching films in class."

S4." “...movies make learning English more fun. Discussing with others can allow us to share ideas of the movie, so we can learn from each other."

S8: "I think using movies in class is a good way to learn English, it helps us to concentrate more and be interested in the lesson."

Participants in the study expressed their desire to have movies used regularly in their English classes. This is a clear indication that the integration of movies was intrinsically motivating in the participants' learning process. Two participants mentioned,

S5: "I like to learn English in this way...I hope we can have the chance to watch movies and discuss them in the class in the future."

S8: “.....With movies, learning can be fun. We were interested and more engaged in the lesson. I hope we can have more movies in the English class"

Students found films more related to their daily lives, as opposed to their textbook. They explained that the movies and the follow-up activities were perfectly planned and useful. Three students commented,

S2: "The activities and the notebook helped me remember the meanings of words better."

S6: "I really think this method is useful, and the activities helped me a lot to understand the movie."

S7: “.....the movie The Devil Wears Prada helped me to write my assignment about describing a family member. It can also help me in the Speaking Assessment."

The majority of the participants welcomed the idea of the use of movies in their lessons. They found that movies are useful for vocabulary learning and acquisition. Two students mentioned,

S3: "This is a great way to enrich our vocabulary through the dialogue in the movie. Movies make me remember the new words so quickly than the reading circles and textbooks; we can use this vocabulary in writing and speaking."

S5: "By watching The Life of Pi, I learned some new vocabulary and phrases that I can use in daily dialogues." 


\subsection{The Teacher's Interviews and Reflective Journals}

An analysis of the interviews conducted with the teachers as well as the reflective journals submitted showed that using movies is a good resource for improving students' language skills.

$\underline{T 2}$ "Movies are a good resource in the English language classroom... It is interesting for the students and... can raise their awareness to how people interact in naturally occurring conversations",

$\underline{T 1}$ "Using movies in the classroom can significantly promote and foster learning as they cater for diverse learning styles and intelligences... movies offer great authentic materials, they expose students to real language... students can learn how people interact in the real world and in everyday situations... they arouse students' emotions, enrich vocabulary acquisition, and motivate them to learn"

They agreed that it was not a waste of time to integrate movies in their classrooms. They believe that movies can help improve students' language skills, vocabulary, grammar, fluency and pronunciation in the English language. They used movies in the classrooms to conduct written activities such as fill in the blanks, summary writing as well as oral activities such as group discussions, film presentations, or role-plays. Teachers in the current study believe that movies should be integrated in the syllabus design and used in the classroom. They also felt that movies helped the students learn about the culture and use of language in daily interaction. The drawback they mentioned was that finding movies that are suitable is important but difficult to do. Choosing appropriate movies is essential to achieve the set goals.

$\underline{T 2}$ "I use movies to engage them in class discussions, to help them learn new words, as well as to get them to do written and oral activities... students are more motivated when the assignments are based on movies..."

$\underline{T 1}$ "They were so interactive and willing to express their opinions, they also learned a wide range of vocabulary and phrases... practiced using some grammatical rules ... primary objective of using movies was to reinforce specific units in their textbook... active in class and responded very well to the activities",

$\underline{T 2}$ “.....they were actively involved in meaningful discussions... stimulated their thinking and imaginations... movies helped the students learn about the culture of the people of the target language and learned how they interact in daily life."

Overall, the findings show that integrating movies in the EFL classroom is an effective pedagogical tool which can help students improve their language skills in terms of their speaking skills, fluency, listening skills, vocabulary acquisition, pronunciation, interactional skills, and colloquial slang. In addition, the findings also indicate that using movies in EFL classrooms can promote learning-oriented interaction, engagement among students, and active learning environment.

\section{Discussion}

The results indicated that the majority of the students agreed that the integration of movies in their English language classes could help them improve their language skills. This supports the results of a study conducted in Turkey (Seferoğlu, 2008) in which the participants acknowledged that besides improving listening and speaking skills, watching movies in English provided them a wealth of knowledge on slang, accents and cross-cultural information. Knee (2001) argues that movies can be integrated into English lessons to foster not only the linguistic competence, but also the interactional competence of the students.

The participants in the current study found that the integration of movies in their classes has significantly increased their motivation to learn the English language. This finding agrees with a study conducted by Florence (2009) which found that films in English provided the participants in his study with authentic contexts as well as motivation to learn the language. The findings of Florence's' study also revealed that movies enabled students to learn faster and remember longer especially in terms of vocabulary; as well as the study in South East Europe (Ismaili, 2013) which concluded that using movies in the classroom stimulated the perceptions of the students directly and made the class livelier and led to more teacher-student discussions. The results of the study support King's (2002) argument that movies in itself is a stimulus, in which learners can be motivated" to communicate in contemporary colloquial English" (King, 2002, p. 33). This can only be accomplished when students are provided with a meaningful and authentic context, in which language proficiency can be improved and students feel less stressed and encouraged to use English as a tool for communication. This also supports the findings of a more recent study which argues that films are highly effective owing to the fact that they "attract the human psyche as they thrill, motivate, shock, entertain and render the masses powerless to resist the temptation of the silver screen" (Macwan, 2015, p. 49).

The findings of the study indicated that movies are valuable authentic materials for improving students' speaking 
skills. The participants found themselves more interactive and engaged in the lessons when the teacher used films more than when the teacher used the textbook or other learning materials. The participants also reported that movies are beneficial for enhancing their interactional skills. Students in the present study reported that through films they were able to learn how native speakers initiate and sustain a conversational exchange, negotiate meaning, and nonverbal communication. This agrees with Katchen's claim (2003) that the textbooks usually do not teach for instance small talk and conversational interaction; thus, movies can be an effective way to motivate learners to develop their interactional skills, since movies usually present the most current and real language with different interactional situations.

The participants in the current study welcomed the exposure to the real English used by native speakers in the movie, which as they mentioned helped them become more confident to speak in English. An authentic and meaningful context is believed to establish a solid ground to effective EFL instruction. This is supported by Eken's argument (2003) that a film's rich and popular context makes it both a medium of enjoyment and a popular of people daily conversations. Accordingly, the participants in this study became more confident and engaged in the discussions and the post-viewing tasks. They also liked the exposure to informal and conversational use of English, which helped them learn the slang and informal phrases used by native speakers.

The majority of the students $(80 \%)$ believed that movies are highly effective in developing their vocabulary acquisition. This finding is in line with a number of studies (Yuksel \& Tanriverdi, 2009; Zarei, 2009; Hsu, Hwang, Chang, \& Chang, 2013) which argued that the integration of movies in the language classroom could significantly enhance and improve the students' vocabulary acquisition, retention, and recognition. Al-Seghayer (2001) confirms that the integration of movies in the EFL classrooms is one of the most effective methods in teaching vocabulary as it provides learners with a rich context that includes a variety of interesting methods to recognize and learn vocabulary.

It can be seen from the results that the students found the pre viewing introduction to the movie of immense help in understanding and comprehending the movie. The teachers who participated also agree that it is important to have activities related to the movie in order to fulfill its pedagogical use. This conclusion also agrees with studies conducted by Keene (2006) which suggests that an anticipatory mind that is made so with the use of an introduction to the movie may contribute to better understanding and contextualization of the new material. Fisher \& Frey (2011) consider viewing full-length feature films an unnecessary waste of good instructional time. Li (2012) concluded in his study that with pre-viewing introductions, which he calls advance organizers, the students are able to remain motivated and know what to listen for without losing focus. King (2002) believes that a pre and post viewing discussions allow students to explore relevant issues raised from a variety of perspectives, develop critical thinking skills, and elicit responses. Moreover, these activities can help students converse freely on all aspects of the film they watch and release them from inhibiting grammatical rule-binding and detailed-oriented learning habits. Stephens et al. (2012) also supported and promoted the use of pre-viewing activities in order to hasten the students' understanding of the movie.

The findings also suggest that movies are unlikely to be useful for learning if the teacher does not provide learning aids. Films can be invaluable pedagogical tools if accompanied with appropriate learning activities. The audiovisual supports provided in the films helped create a meaningful learning experience for the students. This supports the assertion by Soh and Kaur (2007) that students learn faster and better in a rich context provided by movies, which gives them a better understanding of the events portrayed and stimulate more discussions in the classroom.

To conclude, the results of the study indicate that movies can be effective pedagogical tools when used appropriately. King (2002) argues that the integration of movies in language classrooms is effective when meaningful and useful tasks are planned to assist learners along with watching the film. Language instructors should be careful when selecting films for their lessons. Their choice should be based on the interests and the proficiency levels of the students.

\section{Limitations}

There were several limitations to this study. The most prominent one lies in the fact that the sample size was relatively small. The number of the participants in the study was a meagre 50 students. In addition, due to the gender-segregated higher education system in Saudi Arabia, all the participants were female students; thereby, this did not provide variance in population. In addition, the researcher had a limited time frame in which to conduct the study. Moreover, the participants in the current study were all at the same level of proficiency in the English language. If the study was conducted across different proficiency levels, it would have been a more valid manifestation of the effect of using movies in the EFL classrooms. 


\section{Conclusion}

The results of the present study conclude that movies are powerful instructional tools that can help in developing students' language skills. The participants in the study have positive attitudes towards the integration of movies in their classrooms to improve their English. The study also indicates that using movies in the foreign language classroom could enhance the students' motivation to learn the language. Teachers in the current study stated that movies increased students' participation and engagement in the classroom. The students also believed that movies could help improve their vocabulary acquisition as they provide them with a wealth of information about a variety of vocabulary, phrases, and colloquial expressions. However, in order to fulfil its pedagogical purpose, movies should be strategically selected based on the course syllabus, students' interests, and their proficiency level. While designing the tasks and the materials that incorporate the movies into classes, the main goal of using this authentic material and the objectives of the specific lesson should always be kept in mind. In addition, language teachers should not ignore the importance of planning useful and meaningful tasks for students before and after viewing in order to make the teaching focus more explicit, hence students want treat it as a pure source of enjoyment and entertainment.

\section{Acknowledgements}

I would like to express my heartfelt gratitude to my professor, Dr. Abdullah Abargie for his valuable insights, encouragement, and genuine advice. Without his endless support and help, this research might never have been completed. I am deeply thankful to my dearest ELI teachers and students who had taken part in this study for their precious effort, cooperation and enthusiasm during this research. Special thanks must also go to my family for giving me help and motivation throughout the year.

\section{References}

Al-Akloby, S. (2001). Teaching and learning English vocabulary in Saudi Arabian public schools. (PhD Thesis), University of Essex, Exssex, United Kingdom. Retrieved from http://hdl.handle.net/10068/541994

Al-Seghayer, K. (2001). The effect of multimedia annotation modes on L2 vocabulary. Language Learning \& Technology, 5(1), 202-232.

Baddock, B. (1996). Using films in the English class. MEP monographs. Hemel Hempstead: Phoenix ELT.

Baratta, A., \& Jones, S. (2008). Using film to introduce and develop academic writing skills among UK undergraduate students. Journal of Educational Enquiry, 8(2), 15-37.

Bassyonyi, M., \& Cooper, H. (2012). Teaching in style: Interaction patterns in the EFL classroom. Special Edition for the Nile TESOL Conference Proceedings 2012, 2, 139-153.

Berk, R. (2009). Multimedia teaching with video clips: TV, movies, YouTube, and mtvU in the college classroom. International Journal of Technology in Teaching and Learning, 5(1), 1-21.

Brown, S. K. (2010). Popular films in the EFL classroom: Study of methodology. Procedia - Social and Behavioral Sciences, 3, 45-54. http://dx.doi.org/10.1016/j.sbspro.2010.07.011

Chen, M. (2012). Effects of integrating children's literature and DVD films into a college EFL class. English Teaching: Practice and Critique, 11(4), 88-98.

Creswell, J. (2015). A concise introduction to mixed methods research. London, England: SAGE.

Firek, H. (2003). 10 easy ways to use technology in the English classroom. Portsmouth, NH: Heinemann.

Eken, A.N. (2003). "You've got mail": A film workshop. ELT Journal, 57(1), 51-59. http://dx.doi.org/10.1093/elt/57.1.51

Fisher, D., \& Frey, N. (2011). Using videos and film in the classroom: Engaging the adolescent mind. International Reading Association, 1-10.

Florence, Y. (2009). Learning English through films : A case study of a Hong Kong class. University of Hong Kong.

Hayati, A., \& Mohmedi, F. (2011). The effect of films with and without subtitles on listening comprehension of EFL learners. British Journal of Educational Technology, 42(1), 181-192. http://dx.doi.org/10.1111/j.1467-8535.2009.01004.x

Hanley, J., \& Herron, C., A. (1992). Using video to introduce children to a foreign culture. Foreign Language Annals, 25, 419-426. http://dx.doi.org/10.1111/j.1944-9720.1992.tb01122.x

Hill, B. (1999). Video in language learning. Center for Information on Language Teaching and Research: 
London.

Hsu, C.-K., Hwang, G.-J., Chang, Y.-T., \& Chang, C.-K. (2013). Effects of video caption modes on English listening comprehension and vocabulary acquisition using handheld devices. Educational Technology \& Society, 16(1), 403-414.

Ismaili, M. (2013). The effectiveness of using movies in the EFL classroom: A study conducted at South East European University. Academic Journal of Interdisciplinary Studies, 2(4), 121-132. http://dx.doi.org/10.5901/ajis.2012.v2n4p121

Katchen, J., E. (2003). Teaching a listening and speaking course with DVD films: Can it be done? In H. C. Liou, J. E. Katchen, \& H. Wang (Eds.), Lingua Tsing Hu (pp. 221-236). Taipei: Crane.

Keene, M. D. (2006). Viewing video and DVD in the EFL classroom. Bunkyo Gakuin University Journal, 8(1), 217-234.

Khan, A. (2015). Using films in the ESL classroom to improve communication skills of non-native learners. ELT Voices, 5(4), 46-52.

King, J. (2002). Using DVD feature films in the EFL classroom. Computer Assisted Language Learning, 15(5), 509-523. http://dx.doi.org/10.1076/call.15.5.509.13468

Knee. A. (2001). Feature films in language teaching. In G. Brauer (Ed.), Pedagogy of Language Learning in Higher Education: An Introduction (pp. 143-154). Westport, CT, and London: Ablex Publishing.

Krashen, S. D. (1985). The input hypothesis: Issues and implications. Longman Group UK Ltd.

Kusumarasdyati. (2004). Listening, viewing and imagination: Movies in EFL classes. 2nd International Conference on Imagination and Education Vancouver, Canada, July 14-17, 2004.

Li, C. (2012). Are they listening better? Supporting EFL college students' DVD video comprehension with advance organizers in a multimedia English course. Journal of College Teaching \& Learning, 9(4).

Macwan, H. (2015).Using visual aids as authentic material in ESL classrooms. Research Journal of English Language and Literature (RJELAL), 3(1), 91-96.

Martín, M., \& Jaén, M. (2009). Teaching conversation through films: A comparison of conversational features and collocations in the BNC and a micro-corpus of movies. The International Journal of Learning, 16(7), 445-458.

Massi, M., \& Blázquez, B. (2008). Exploiting DVDs' extra features: An added bonus in the EFL class. Humanising Language Teaching, 10(4).

Mirvan, X. (2013).The advantages of using films to enhance student's reading skills in the EFL classroom. Journal of Education Practice, 4(13).

Pezdeck, K., Lehrer, A., \& Simon, S. (1984). The Relationship between reading and cognitive processing of television and radio. Child Development, 55, 2072-2082. http://dx.doi.org/10.2307/1129780

Rokni, S., \& Ataee, A. (2014). Movies in EFL classrooms: With or without subtitles. The Dawn Journal, 3(1), 715-726.

Ruusunen, V. (2011). Using movies in EFL teaching: The point of view of teachers. Master's Thesis.

Seferoğlu, G. (2008). Using feature films in language classes. Educational Studies, 34(1), 1-9. http://dx.doi.org/10.1080/03055690701785202

Soh, G. E., \& Kaur, H. (2007). The use of films to promote critical thinking in the English language. In C. Tan (Ed.), Engaging films \& music videos in critical thinking (pp. 139-153). Singapore: McGraw-Hill.

Stempleski, S., \& Tomalin, B. (2001). Film. Oxford: Oxford University Press.

Stempleski, S. (2002). Video in the ELT classroom: The role of the teacher. In J. Richards, \& W. Renandya (Eds.), Methodology in language teaching: An anthology of current practice. Cambridge: Cambridge University Press. http://dx.doi.org/10.1017/CBO9780511667190.052

Stephens, C., Ascencio, R., Burgos, A., Diaz, T., Montenegro, J., \& Valenzuela, C. (2012). Film circles: Scaffolding speaking for EFL students. English Teaching Forum, 2, 14-20.

Swaffar, J., \& Vlatten. (1997). A sequential model for video viewing in the foreign language curriculum. Modern Language Journal, 81, 175-88. http://dx.doi.org/10.1111/j.1540-4781.1997.tb01173.x 
Teddlie, C., \& Yu, F. (2007). Mixed methods sampling: A typology with examples. Journal of Mixed Methods Research, 1(1), 77-100. http://dx.doi.org/10.1177/2345678906292430

Tognozzi, E. (2010). Teaching and evaluating language and culture through film. ITALICA, 87(1), 69-91.

Yaseen, B., \& Shakir, H. (2015). Movies effects on EFL learners at Iraqi school in Kuala Lumpur. International Journal of Education and Literacy Studies, 3(3), 31-36. http://dx.doi.org/10.7575/aiac.ijels.v.3n.3p.31

Yuksel, D., \& Tanriverdi, B. (2009). Effects of watching captioned movie clip on vocabulary development of EFL learners. The Turkish Online Journal of Educational Technology - TOJET, 8(2), 48-54.

Zarei, A. (2009). The effect of bimodal, standard, and reversed subtitling on L2 vocabulary recognition and recall. Pazhuhesh-e Zabanha-ye Khareji, 49, 65-85.

Zhang, Q. (2013). The impact of film and film-based activities on the attitudes of English speaking secondary-school students toward L2 Chinese. Creative Practices in Language Learning and Teaching (CPLT), 1(2), 1-17.

\section{Copyrights}

Copyright for this article is retained by the author(s), with first publication rights granted to the journal.

This is an open-access article distributed under the terms and conditions of the Creative Commons Attribution license (http://creativecommons.org/licenses/by/3.0/). 